\title{
PERBEDAAN MUSIM TANAM TERHADAP PERFORMA BUDIDAYA EMPAT VARIAN RUMPUT LAUT EUCHEUMATOIDS DI TELUK GERUPUK, NUSA TENGGARA BARAT
}

\author{
Erlania dan I Nyoman Radiarta \\ Pusat Penelitian dan Pengembangan Perikanan Budidaya \\ Jl. Ragunan 20, Pasar Minggu, Jakarta Selatan 12540 \\ E-mail: erlania_elleen@yahoo.com
}

(Naskah diterima: 12 Desember 2013; Disetujui publikasi: 4 Juni 2014)

\begin{abstract}
ABSTRAK
Musim tanam rumput laut di perairan Teluk Gerupuk dikelompokkan menjadi musim produktif dan non-produktif. Penelitian ini bertujuan untuk menganalisis perbedaan performa budidaya dari empat varian rumput laut: Kappaphycus alvarezii varian Tambalang dan Maumere, Eucheuma denticulatum, dan K. striatum yang dibudidayakan di perairan Teluk Gerupuk dengan metode long line pada musim tanam yang berbeda. Pengamatan terhadap parameter performa budidaya meliputi laju pertumbuhan harian, pertambahan biomassa, dan produksi rumput laut, yang dilakukan setiap 15 hari sekali selama masa budidaya yaitu 45 hari per siklus. Pengamatan dilakukan selama tiga siklus tanam dari bulan Juli-Desember. Analisis ragam (ANOVA) dengan rancangan acak lengkap faktorial dan uji lanjut Tukey Test dilakukan untuk mengetahui pengaruh perbedaan varian rumput laut dan periode musim tanam terhadap parameter yang diamati. Hasil penelitian menunjukkan bahwa musim tanam (produktif dan non-produktif) merupakan salah satu aspek penting yang berpengaruh nyata terhadap performa budidaya rumput laut $(P<0,05)$. Dari keempat varian yang dibudidayakan, $E$. denticulatum merupakan varian yang memiliki performa terbaik yang berbeda nyata dengan ketiga varian lainnya $(P<0,05)$, baik pada musim produktif maupun musim non-produktif. Pemilihan varian rumput laut yang tepat dengan tingkat pertumbuhan dan daya adaptasi yang lebih baik terhadap perbedaan kondisi lingkungan merupakan salah satu kunci keberhasilan dan keberlanjutan budidaya rumput laut.
\end{abstract}

KATA KUNCl: musim tanam, pertumbuhan, rumput laut, eucheumatoids, Teluk Gerupuk

ABSTRACT: Seasonal cultivatian periods of four Eucheumatoids seaweeds variants performance in Gerupuk Bay, West Nusa Tenggara. By: Erlania and I Nyoman Radiarta

Seaweeds cultivation periods was grouped into productive and non-productive season. This study was conducted to analyze culture performance of four seaweeds variants: Kappaphycus alvarezii variant Tambalang and Maumere, Eucheuma denticulatum, and $\mathrm{K}$. striatum, that were cultivated with long line method during difference cultivation periods in Gerupuk Bay. Parameters of culture performance which included daily growth rate, biomass increasement, and yield were observerd every 15 days during 45 days for each culture period. The observation was conducted in three cultivation periods starting from July-December. Analysis of variance (ANOVA) with completely randomized-factorial design and Tukey Test were used to observe the influences of seaweed variants and seasonal cultivation periods on culture performance 
parameters. The results showed that seasonal cultivatian periods (productive and non-productive) indicated significantly difference $(P<0.05)$ in influencing seaweeds performances. E. denticulatum had the best performance and significantly difference $(P<0.05)$ among three seaweed variants, either in productive or nonproductive cultivation periods. The appropriate selection of seaweed variants, which had the highest growth rate and adaptation capability at the different environmental conditions, is one of the key factors for supporting success and sustainable seaweed cultivation.

KEYWORDS: seasonal cultivation periods, growth rate, seaweeds, eucheumatoids, Gerupuk Bay

\section{PENDAHULUAN}

Rumput laut merupakan komoditas unggulan sektor kelautan dan perikanan yang menjadi penyumbang terbesar dari total produksi perikanan nasional sejak beberapa tahun terakhir. Produksi rumput laut di Indonesia menunjukkan peningkatan yang sangat signifikan, yaitu dari sekitar 223 ribu ton pada tahun 2002 menjadi 4,54 juta ton pada tahun 2011 (DJPB, 2012). Upaya peningkatan produksi terus dilakukan melalui identifikasi kawasan potensial pengembangan di setiap lokasi. Pengembangan kawasan budidaya rumput laut dapat dipengaruhi oleh kondisi lingkungan biofisik perairan dan kondisi iklim. Hal ini disebabkan kondisi perairan yang bersifat sangat dinamis, serta adanya pengaruh iklim yang akhir-akhir ini tidak dapat diprediksi (De Silva \& Soto, 2009). Kegagalan panen sering dialami oleh pembudidaya rumput laut yang banyak disebabkan oleh terjadinya gelombang besar yang menghancurkan media dan rumput laut budidaya, serta adanya dampak perubahan iklim berupa curah hujan yang sangat tinggi ataupun musim panas yang panjang. Hal ini menyebabkan rumput laut sangat rentan terhadap munculnya penyakit seperti ice-ice.

Kappaphycus alvarezii (Doty) Doty, Eucheuma denticulatum (Collins et Harvey), dan K. striatum (Doty) baik yang berasal dari alam maupun hasil budidaya; merupakan sumber utama dari jenis rumput laut penghasil senyawa hidrokoloid bernilai ekonomis tinggi yaitu karaginan (Ask \& Azanza, 2002). 'Cottonii' merupakan nama komersil dari kedua spesies Kappaphycus tersebut yang menghasilkan kappa-karaginan, sedangkan "spinosum" merupakan nama komersil dari E. denticulatum yang menghasilkan iota-karaginan; ketiga spesies tersebut merupakan jenis komersial dari kelompok Eucheumatoids (Santos, 1989 dalam Ask \& Azanza, 2002).
Setiap jenis rumput laut memiliki karakteristik yang berbeda-beda dan spesifik terkait kemampuannya untuk hidup, beradaptasi, dan tumbuh pada kondisi lingkungan perairan tertentu. Perubahan musim secara global akan berdampak pada terjadinya perubahan kondisi lingkungan perairan. Kemampuan dari setiap jenis rumput laut untuk dapat mengurangi atau bahkan mengeliminir dampak negatif dari perubahan kondisi lingkungan yang disebabkan oleh perubahan musim terhadap laju pertumbuhan dan kualitas karaginan yang dihasilkan, akan menjadi salah satu karakteristik unggulan (Ask \& Azanza, 2002). Jenis rumput laut tersebut berpeluang untuk menjadi komoditas budidaya yang adaptif dan dapat dikembangkan secara luas melalui kegiatan budidaya.

Ask \& Azanza (2002) menyatakan bahwa hal pertama yang harus dilakukan untuk dapat mengetahui bagaimana pola musiman rumput laut eucheumatoids yaitu dengan pengamatan terhadap parameter tanaman (laju pertumbuhan, insidensi penyakit ice-ice, dan jumlah biomassa yang hilang) dan parameter lingkungan (suhu, salinitas, dan pergerakan air). Penelitian terkait telah dilakukan oleh Erlania (2013), Erlania et al. (2013), Raikar et al. (2001), Bulboa \& de Paula (2005), dan Thirumaran \& Anantharaman (2009) terhadap berbagai jenis rumput laut dari kelompok Rhodophyta. Sejumlah karakter lingkungan perairan dapat memengaruhi pertumbuhan rumput laut; beberapa faktor utama yang paling berpengaruh nyata terhadap pertumbuhan dan proses fotosintesis pada rumput laut yaitu suhu, salinitas, dan intensitas cahaya, serta dessication atau kekeringan akibat perubahan kondisi pasang-surut (Dawes, 1981; Raikar et al., 2001; Muñoz et al., 2004; Banerjee et al., 2009). Menurut Ask \& Azanza (2002), faktor musim dapat menyebabkan terjadinya perubahan besar dari faktor-faktor lingkungan 
pada lokasi budidaya; jika rumput laut menunjukkan performa yang tidak baik selama bulan-bulan tertentu dalam setahun karena terjadinya perubahan ekstrim dari faktor-faktor lingkungan, maka relokasi aktivitas budidaya perlu menjadi pertimbangan. Akan tetapi, hal ini akan membutuhkan upaya dan biaya yang cukup besar. Dengan demikian, diperlukan kajian terhadap berbagai jenis rumput laut terkait daya adaptasinya terhadap perubahan kondisi lingkungan yang dipengaruhi oleh perubahan musim. Penelitian ini bertujuan untuk menganalisis perbedaan performa budidaya dari empat varian rumput laut, Kappaphycus alvarezii varian Tambalang dan Maumere, Eucheuma denticulatum, dan $K$. striatum, yang dibudidayakan di perairan Teluk Gerupuk pada musim tanam yang berbeda.

\section{BAHAN DAN METODE}

Penelitian telah dilakukan di perairan Teluk Gerupuk, Kabupaten Lombok Tengah, Nusa Tenggara Barat (Gambar 1). Budidaya rumput laut dilakukan selama tiga siklus dari bulan Juli-Desember 2013. Satu siklus berlangsung selama 45 hari; siklus-1 sampai dengan siklus3 dilakukan masing-masing pada periode JuliAgustus, September-Oktober, dan NovemberDesember.
Bibit rumput laut yang digunakan diperoleh dari pembudidaya lokal di Lombok Tengah dan Lombok Timur, yang terdiri atas empat varian rumput laut dari kelompok Rhodophyta. Keempat varian rumput laut tersebut yaitu Kappaphycus alvarezii varian Tambalang dan varian Maumere yang dikenal dengan nama komersil cottonii, K. striatum yang dikenal dengan nama umum sacol/cottonii, dan Eucheuma denticulatum yang dikenal dengan sebutan spinosum. Metode budidaya rumput laut dilakukan dengan sistem long line (SNI 7579.2:2010 dan BBL, 2012). Unit long line yang digunakan berukuran $50 \mathrm{~m} \times 50 \mathrm{~m}$; terdiri atas tali utama pada empat sisi unit long line dan 24 line (tali ris) masing-masing sepanjang 50 meter yang dibentangkan pada tali utama. Bibit rumput laut diikatkan pada setiap line dengan bobot rata-rata $100 \mathrm{~g}$; pada satu line terdapat 250 titik ikatan bibit rumput laut. Masing-masing varian rumput laut dibudidayakan pada enam line secara bersamaan dalam satu unit long line. Talus muda dari rumput laut yang dipanen pada siklus- 1 dijadikan bibit yang ditanam kembali pada siklus-2, dan seterusnya hingga siklus-3.

Desain penelitian yang digunakan adalah rancangan acak lengkap (RAL) faktorial dengan faktor perlakuan varian rumput laut (Kappaphycus alvarezii varian Tambalang dan

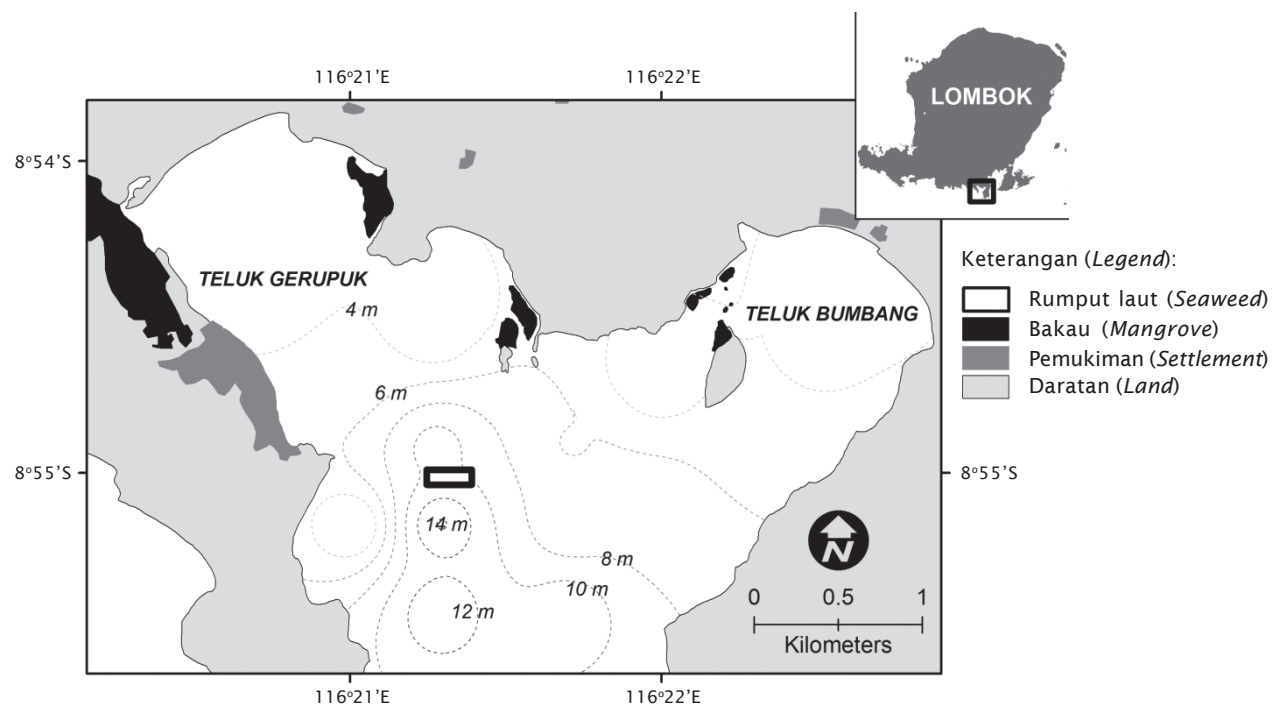

Gambar 1. Peta lokasi penelitian di Teluk Gerupuk, Lombok Tengah, Nusa Tenggara Barat, dan posisi budidaya rumput laut

Figure 1. Map of the study area in Gerupuk Bay, Central Lombok, West Nusa Tenggara, and position of seaweeds aquaculture 
varian Maumere, K. striatum, Eucheuma denticulatum) dan periode musim tanam (musim produktif dan non-produktif) dengan lima ulangan. Pengamatan terhadap performa rumput laut dilakukan setiap 15 hari sejak awal tanam yaitu pada hari ke-0 (tanam), 15, 30, dan 45 pemeliharaan. Pada setiap waktu pengamatan dilakukan pengambilan sampel dari masing-masing varian rumput laut dengan metode sampling-panen sebanyak lima titik tanam, kemudian ditimbang bobot basahnya. Selain itu, juga dilakukan pengukuran dua parameter fisik kualitas perairan yang merupakan faktor utama yang paling berpengaruh nyata terhadap pertumbuhan rumput laut yaitu suhu dan salinitas (Dawes, 1981), yang dilakukan setiap bulan selama masa penelitian.

Parameter penelitian yang diamati berupa performa budidaya rumput laut yang meliputi laju pertumbuhan harian, pertambahan biomassa, dan produksi rumput laut. Laju pertumbuhan harian (Daily growth rate/DGR) rumput laut dikalkulasikan berdasarkan persamaan sebagai berikut (Lüning, 1990; Dawes et al., 1993):

$$
\operatorname{DGR}(\%)=\frac{100 \ln \left(W_{f} / W_{o}\right)}{T}
$$

di mana:

$\mathrm{W}_{\mathrm{f}}=$ Bobot basah rumput laut per titik sampling pada akhir pemeliharaan $(\mathrm{g})$

$\mathrm{W}_{\mathrm{o}}=$ Bobot basah rumput laut per titik sampling pada awal tanam (g)

$\mathrm{T}=$ Waktu pemeliharaan (hari)

Pertambahan biomassa $(\Delta \mathrm{B})$ rumput laut diamati antar segmen umur pemeliharaan yaitu setiap 15 hari dan dikalkulasikan per satuan tali ris/line sebagai satuan percobaan pada desain penelitian ini, dengan formula sebagai berikut:

$$
\Delta \mathrm{B}(\mathrm{kg} / \text { line })=\frac{\mathrm{W}_{\mathrm{f}} \times \mathrm{n}}{1000}
$$

di mana:

$\mathrm{W}_{\mathrm{f}}=$ Bobot basah rumput laut per titik sampling pada akhir pemeliharaan $(\mathrm{g})$

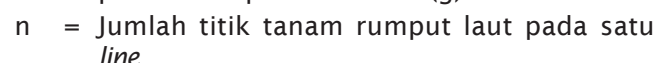

Produksi (Y) rumput laut pada akhir pemeliharaan yang dinyatakan dengan satuan $\mathrm{kg} / \mathrm{m} /$ line digunakan formula Doty (1986) yang dimodifikasi oleh Hurtado (2001) sebagai berikut:

$$
Y=\frac{W_{f}-W_{o}}{L_{t}}
$$

di mana:

$\mathrm{W}_{\mathrm{f}}=$ Bobot akhir rumput laut

$\mathrm{W}_{\mathrm{o}}=$ Bobot awal rumput laut

$\mathrm{L}_{\mathrm{t}}=$ Panjang satu line atau tali ris yang digunakan untuk budidaya rumput laut

Analisis ragam (ANOVA) dilakukan untuk menganalisis pengaruh perbedaan varian rumput laut dan periode musim tanam terhadap parameter-parameter performa budidaya yang diamati. Jika respons yang dihasilkan berbeda nyata maka dilakukan uji lanjut menggunakan Tukey Test (Honestly Significant Difference) HSD). Selain itu, dilakukan juga analisis data dari tiap-tiap parameter secara deskriptif yang ditampilkan dalam bentuk gambar.

\section{HASIL DAN BAHASAN}

\section{Determinasi Musim Tanam Rumput Laut di Teluk Gerupuk, Nusa Tenggara Barat}

Berdasarkan data klimatologi sepanjang tahun 2013 yang diperoleh dari stasiun Meteorologi Klimatologi dan Geofisika Bandara Internasional Lombok (Gambar 2), kecenderungan pola parameter iklim hampir sama dengan dua tahun sebelumnya yaitu tahun 2011 dan 2012 (Radiarta et al., 2013; Erlania, 2013). Pada pertengahan bulan Mei hingga mendekati akhir Oktober merupakan periode di mana suhu udara relatif rendah yaitu berkisar antara $22,3^{\circ} \mathrm{C}-27,0^{\circ} \mathrm{C}$. Selanjutnya pada akhir Oktober suhu udara mulai meningkat dan semakin tinggi hingga akhir Desember dengan kisaran $25,2^{\circ} \mathrm{C}-29,3^{\circ} \mathrm{C}$. Suhu udara secara tidak langsung memengaruhi suhu perairan yang selanjutnya akan memengaruhi pertumbuhan rumput laut.

Kecepatan angin pada periode Juli-Oktober relatif lebih tinggi dibandingkan periode November-Desember (Gambar 2). Kisaran kecepatan angin pada periode Juli-Oktober yaitu 4,6-13,2 knot; sedangkan pada periode November-Desember 4,1-10,2 knot. Rata-rata curah hujan selama periode Juli-Oktober hanya $3,8 \mathrm{~mm}$. Pada periode ini kejadian hujan sangat jarang, bahkan dapat dianggap termasuk pada musim kering (Gambar 2). Pada periode OktoberDesember rata-rata curah hujan relatif lebih tinggi yaitu 12,9 mm. Pada Gambar 2 juga dapat terlihat bahwa frekuensi terjadinya hujan jauh 
lebih tinggi dibandingkan periode Juli-Oktober. Periode November-Desember ini termasuk pada periode musim hujan. Perbedaan curah hujan yang terjadi pada musim produktif dan non-produktif berpengaruh pada salinitas perairan. Selain itu, curah hujan juga berkorelasi dengan suhu udara (Gambar 2). Hal ini juga diperlihatkan pada hasil penelitian Radiarta et al. (2013) bahwa pada saat curah hujan minimum, suhu udara secara umum menunjukkan nilai terendah, atau sebaliknya.
Periode penelitian yang berlangsung pada bulan Juli-Oktober dengan kondisi suhu udara yang relatif rendah, kecepatan angin tinggi dan tidak terlalu fluktuatif, serta curah hujan yang sangat rendah merupakan kondisi optimum untuk aktivitas budidaya rumput laut di Teluk Gerupuk, karena pada kondisi tersebut parameter kualitas perairan terutama suhu dan salinitas relatif tidak mengalami fluktuasi yang terlalu ekstrim (Radiarta et al., 2013; Erlania, 2013).
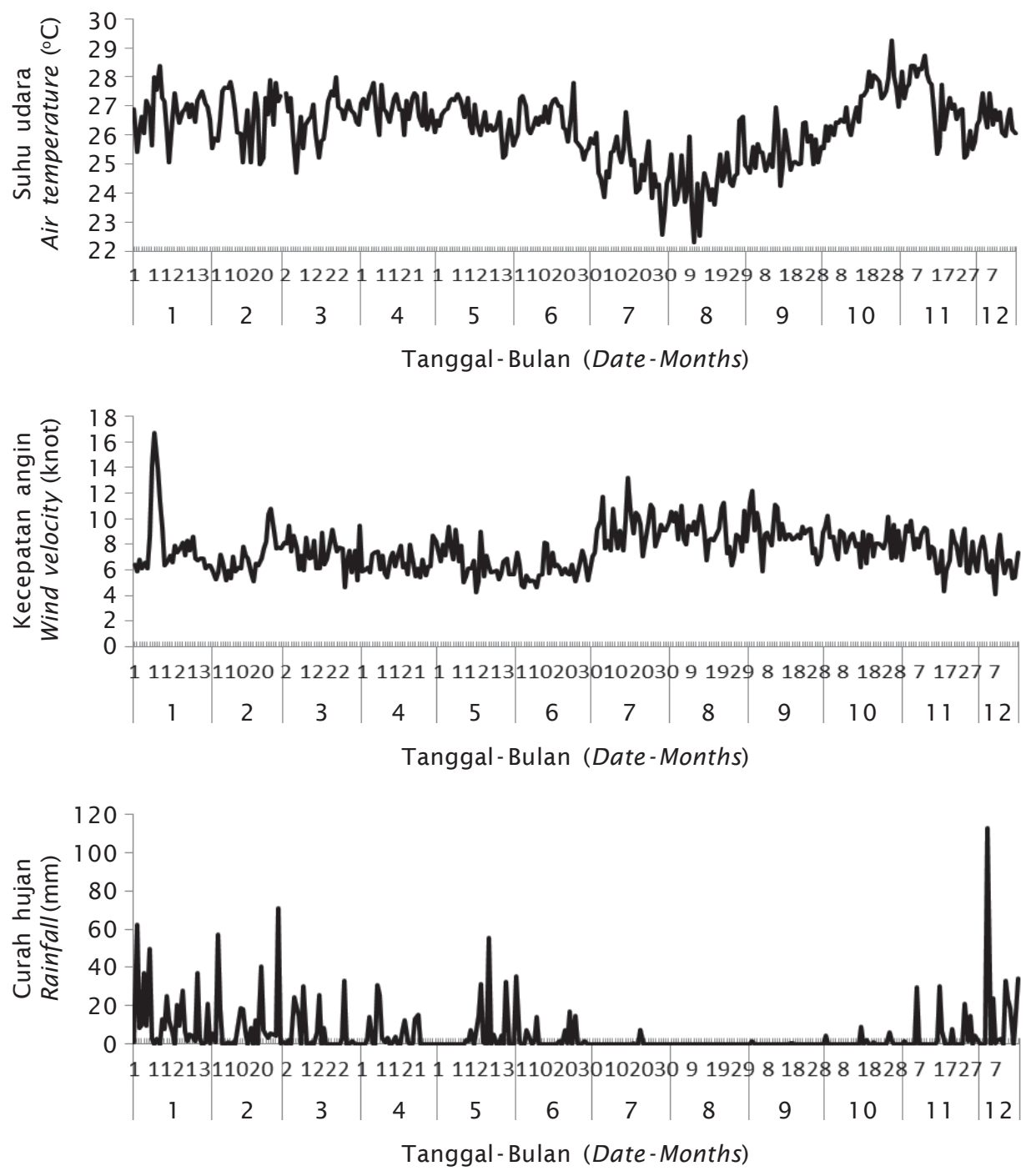

Gambar 2. Fluktuasi parameter iklim (suhu udara, kecepatan angin, curah hujan) yang mencakup wilayah penelitian selama tahun 2013

Figure 2. Climate parameters fluctuation (air temperature, wind velocity, rainfall) covering research area during 2013 
Berdasarkan kondisi parameter iklim selama tahun 2013 (Gambar 2), maka periode penelitian yang berlangsung dari bulan JuliDesember tahun 2013 ini dapat dikategorikan ke dalam dua musim tanam, yaitu periode JuliOktober yang merupakan musim produktif (produktivitas budidaya rumput laut tinggi), dan periode November-Desember sebagai musim kurang/tidak produktif (produktivitas budidaya rumput laut rendah). Pengelompokan musim tanam rumput laut pada tahun 2013 ini relatif sama dengan hasil penelitian Radiarta et al. (2013) terkait musim tanam rumput laut di Teluk Gerupuk pada tahun 2007-2012; musim tanam produktif berlangsung dari bulan Mei/Juni hingga Oktober, sedangkan musim tanam non-produktif berlangsung dari bulan November hingga bulan April/Mei; kecuali pada tahun 2009 dan 2010 terjadi pergeseran musim tanam rumput laut di lokasi tersebut. Berdasarkan hasil penelitian Radiarta et al. (2013) juga terlihat bahwa pada tahun 2013 terdapat pola musim tanam yang sama dengan tahun 2011-2012.

Berdasarkan hasil survai lapangan, pada awal musim non-produktif umumnya aktivitas budidaya rumput laut oleh pembudidaya di perairan Teluk Gerupuk mulai menurun intensitasnya. Sekitar bulan Januari-April/Mei bahkan tidak dilakukan aktivitas budidaya rumput laut sama sekali, karena pada musim tersebut pertumbuhan rumput laut cenderung sangat lambat, dan juga sering terkena penyakit dan parasit (Radiarta et al., 2013), sehingga jika dilakukan budidaya rumput laut pada periode tersebut, akan menimbulkan kerugian yang cukup berarti bagi pembudidaya. Aktivitas budidaya yang masih ada hanya dilakukan untuk tujuan mempertahankan ketersediaan bibit rumput laut di lokasi tersebut hingga masuknya awal musim produktif sekitar akhir bulan Mei atau awal Juni.

Determinasi musim tanam di Teluk Gerupuk ini juga didukung oleh data parameter utama kualitas air yang berperan dalam pertumbuhan rumput laut, yaitu suhu dan salinitas perairan. Kisaran suhu perairan selama penelitian pada musim produktif yaitu $26,2^{\circ} \mathrm{C}-29,0^{\circ} \mathrm{C}$ dengan rata-rata $27,06^{\circ} \mathrm{C}$; relatif lebih rendah dibandingkan pada musim non-produktif yaitu berkisar $27,4^{\circ} \mathrm{C}-29,6^{\circ} \mathrm{C}$ dengan rata-rata $28,72^{\circ} \mathrm{C}$. Hasil penelitian Muñoz et al. (2004) menunjukkan bahwa suhu perairan berkorelasi negatif dengan laju pertumbuhan harian K. alvarezii yang dibudidayakan di perairan tropis Yucatán,
México. Dengan demikian, kisaran suhu perairan yang lebih rendah pada musim produktif merupakan kondisi yang optimum bagi pertumbuhan rumput laut; dengan catatan masih berada dalam kisaran toleransi bagi pertumbuhan rumput laut (Parenrengi et al., 2011). Kisaran salinitas perairan Teluk Gerupuk pada musim produktif yaitu 34,82-35, 17 ppt dengan rata-rata $35,02 \mathrm{ppt}$; sedangkan pada musim non-produktif salinitas perairan relatif lebih rendah yaitu berkisar antara 34,25-35,05 ppt dengan rata-rata 34,82 ppt. Hasil penelitian Scherner et al. (2012) terhadap Ulva lactuca dan Sargassum stenophyllum menunjukkan efek yang berbeda dari perbedaan perlakuan suhu dan salinitas terhadap kedua spesies tersebut; produksi maksimum dari U. lactuca lebih dipengaruhi oleh faktor suhu, sedangkan S. stenophyllum lebih dipengaruhi oleh faktor salinitas. Menurut Wong \& Chang (1999), Grateloupia filicina (rhodophyta) menunjukkan respons fotosintesis optimum pada salinitas 20 ppt, dan menurun pada salinitas lebih ataupun kurang dari 20 ppt. Scherner et al. (2012) juga menyatakan bahwa kondisi pertumbuhan rumput laut dapat mengalami perubahan jika salinitas mengalami penurunan yang ekstrim dan terjadi secara berulang kali.

\section{Performa Budidaya Empat Varian Rumput Laut Terhadap Perbedaan Musim Tanam}

Pertumbuhan rumput laut dipengaruhi oleh jenis/varietas, lokasi, dan musim tanam; sehingga evaluasi pertumbuhan rumput laut sangat penting dilakukan dalam rangka pemilihan jenis yang sesuai dengan lokasi dan musim tanam (Parenrengi et al., 2011). Secara umum, laju pertumbuhan harian keempat rumput laut yang diuji dalam penelitian ini lebih tinggi pada periode Juli-Agustus dan September-Oktober yang termasuk pada musim tanam produktif, dibandingkan periode November-Desember yang dikategorikan sebagai musim non-produktif (Gambar 3 ). Banerjee et al. (2009) juga menyatakan bahwa rumput laut akan menerima efek yang ditimbulkan oleh variasi musiman faktor abiotik dari lingkungannya, yang akan memengaruhi respons metabolik berupa laju pertumbuhan dan laju fotosintesis.

Hasil analisis ragam terhadap faktor periode budidaya maupun varian rumput laut, menunjukkan respons laju pertumbuhan harian rumput laut yang berbeda nyata antar 


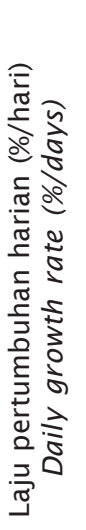

(a) Juli-Agust
Musim produktif

Productive season
Musim non-produktif

Non-productive season

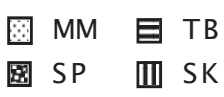
a

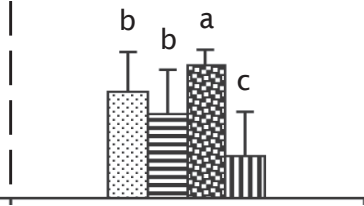

(b) Nov-Des

(a) Sep-Okt

Periode budidaya (Cultivation periods)

Gambar 3. Rata-rata laju pertumbuhan harian rumput laut pada tiga siklus budidaya di Teluk Gerupuk (MM: K. alvareziivar. Maumere, TB: K. alvarezii var. Tambalang, SP: Eucheuma denticulatum, SK: K. striatum). Huruf yang berbeda menunjukkan hasil yang berbeda nyata $(\mathrm{P}<0,05)$

Figure 3. Average daily growth rate of seaweeds from three cultivation periods in Gerupuk Bay (MM: K. alvarezii var. Maumere, TB: K. alvarezii var. Tambalang, SP: Eucheuma denticulatum, SK: K. striatum). Different letters indicate the significant different of the results $(P<0.05)$

varian rumput laut dan periode budidaya tersebut $(P<0,01)$. Secara deskriptif pada Gambar 3 dapat terlihat bahwa pada musim produktif maupun non-produktif, $E$. denticulatum memiliki rata-rata laju pertumbuhan harian yang tertinggi yang berkisar antara 2,37\%-5,88\%/ hari; sedangkan $K$. striatum memperlihatkan laju pertumbuhan harian terendah di antara keempat varian tersebut yaitu antara $0,16 \%$ 2,57\%/hari. Sementara itu, K. alvarezii, baik varian Maumere maupun Tambalang memiliki rata-rata laju pertumbuhan harian yang relatif hampir sama yaitu berturut-turut 1,89\%-4,19\%/ hari dan 1,49\%-3,84\%/hari. Hal ini sesuai dengan hasil uji lanjut menggunakan Tukey Test yang memperlihatkan bahwa keempat varian rumput laut menghasilkan rata-rata laju pertumbuhan harian yang berbeda nyata antar musim tanam $(P<0,05)$. Sedangkan untuk faktor varian rumput menunjukkan bahwa K. alvarezii varian Maumere dan Tambalang menghasilkan respons rata-rata laju pertumbuhan harian yang sama, dan berbeda nyata dengan dua varian lainnya $(P<0,05)$. Hasil penelitian Hutardo et al. (2001) menunjukkan bahwa laju pertumbuhan harian tertinggi dari dua varian K. alvarezii (varian coklat dan hijau) pada musim puncak/produktif berturut-turut antara 0,2\%-4,2\%/hari dan 0,9\%-3,9\%/hari.
Perbedaan tren pertumbuhan dari keempat varian rumput laut tersebut yang dibudidayakan pada musim tanam berbeda, secara lebih spesifik dapat tergambar dari gradien pertambahan biomassa rumput laut tersebut yang diamati pada setiap segmen umur pemeliharaan, yaitu setiap 15 hari sekali (Gambar 4). Pada musim tanam produktif terlihat bahwa tren pertambahan biomassa rumput laut relatif sama pada kedua periode budidaya (JuliAgustus dan September-Oktober). Pada kedua periode budidaya yang berlangsung pada musim produktif, $E$. denticulatum menunjukkan pertambahan biomassa yang paling tinggi di antara keempat varian yang dibudidayakan (Gambar 3 dan 4). Hal ini mengindikasikan bahwa $E$. denticulatum memiliki karakteristik pertumbuhan dan kemampuan adaptasi yang lebih baik terhadap lingkungan dibandingkan tiga varian lainnya. Parenrengi et al. (2011) melaporkan bahwa $E$. denticulatum memperlihatkan ritme pertumbuhan yang lebih baik dibandingkan K. alvarezii (varian coklat dan hijau) yang dibudidayakan dengan sistem long line pada lokasi yang sama di perairan Sulawesi Selatan.

Pada musim non-produktif, terlihat secara jelas bahwa gradien pertambahan biomassa 

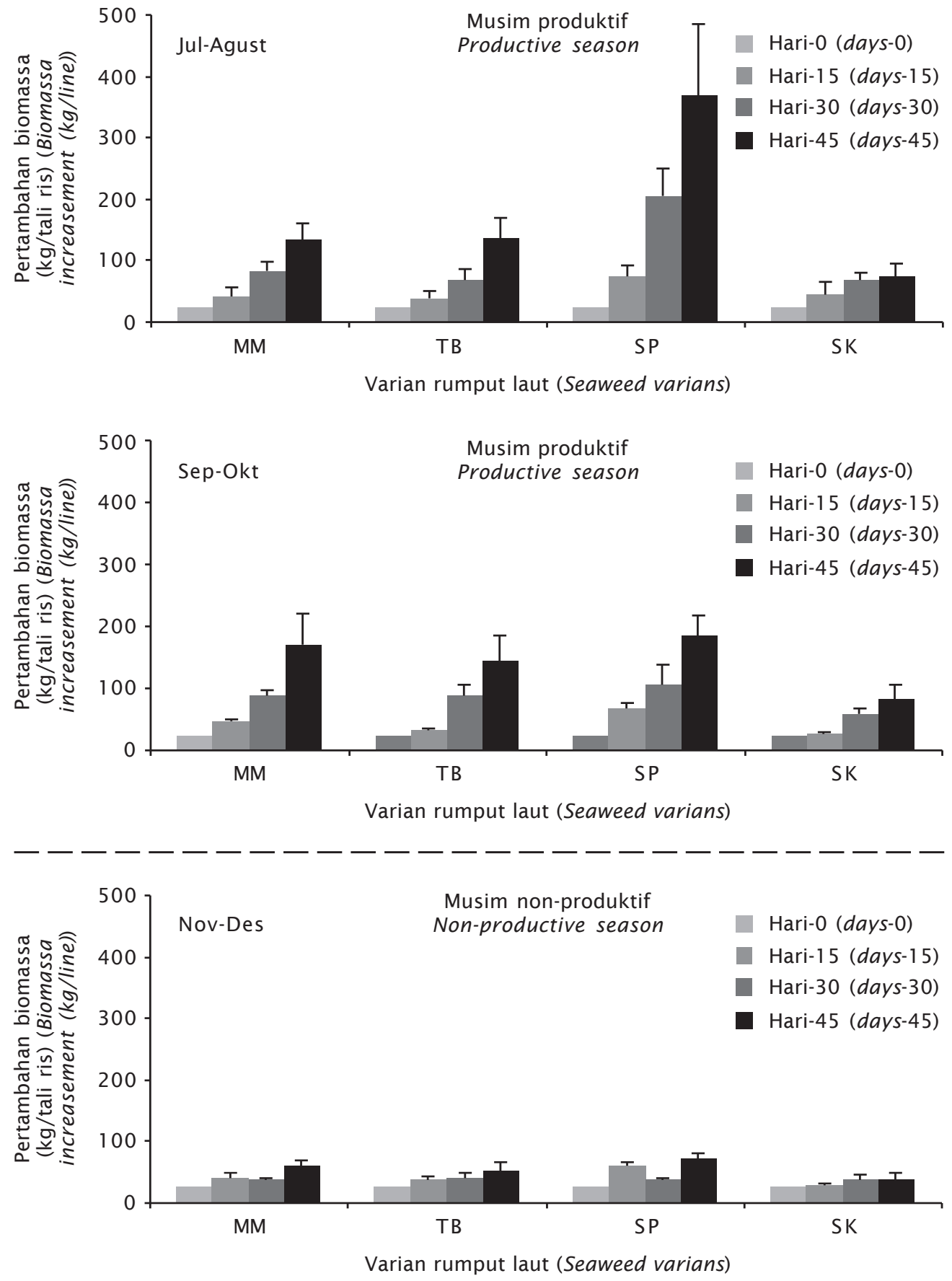

Gambar 4. Rata-rata peningkatan biomassa rumput laut selama pemeliharaan pada tiga siklus budidaya di Teluk Gerupuk (MM: K. alvareziivar. Maumere, TB: K. alvarezii var. Tambalang, SP: Eucheuma denticulatum, SK: K. striatum)

Figure 4. Average biomass increasement of seaweeds during cultivation from three cultivation periods in Gerupuk Bay (MM: K. alvarezii var. Maumere, TB: K. alvarezii var. Tambalang, SP: Eucheuma denticulatum, SK: K. striatum) 
rumput laut dari hari ke-0 hingga hari ke- 45 relatif rendah dibandingkan pada musim produktif (Gambar 4). Pada musim non-produktif, biomassa keempat varian rumput laut antar segmen umur yang diamati tidak menunjukkan peningkatan yang berarti. Rata-rata biomassa akhir rumput laut pada hari ke-45 berturut-turut hanya $59,31 \mathrm{~kg} /$ line; $40,95 \mathrm{~kg} /$ line; dan $73,11 \mathrm{~kg} /$ line untuk K. alvarezii var. Maumere, K. alvarezii var. Tambalang, dan $E$. denticulatum; dengan biomassa awal sekitar $25 \mathrm{~kg} /$ line. Sedangkan K. striatum menunjukkan biomassa akhir hanya 16,15 kg/line yang lebih rendah dibandingkan dengan biomassa awal yaitu $25 \mathrm{~kg} /$ line. Berdasarkan kondisi budidaya di lapangan, rendahnya pertambahan biomassa rumput laut budidaya disebabkan karena talusnya banyak mengalami kerusakan dan rontok akibat kondisi musim tanam yang kurang baik (musim non-produktif). Hasil penelitian Banerjee et al. (2009) mengindikasikan bahwa biomassa yang dihasilkan Catenella repens yang termasuk salah satu spesies dari kelompok Rhodophyta, lebih tinggi pada periode sebelum musim hujan dibandingkan pada musim hujan. Musim nonproduktif pada wilayah Teluk Gerupuk salah satunya dicirikan dengan berlangsungnya musim hujan.
Rendahnya pertambahan biomassa rumput laut yang dihasilkan pada musim non-produktif di antaranya disebabkan oleh faktor tingginya curah hujan pada musim tersebut (Gambar 2 dan 4). Pada musim penghujan salinitas perairan mengalami penurunan dan rumput laut akan merespons kondisi tersebut secara fisiologis melalui proses osmoacclimation (Lüning, 1990). Salinitas perairan yang rendah akan menyebabkan proses aliran air mengikuti gradien osmotik yaitu dari lingkungan ke dalam sel rumput laut; yang berdampak pada perubahan tekanan turgor sel sehingga mengakibatkan kondisi rumput laut menjadi tidak stabil, rapuh dan secara perlahan talus akan patah dan rontok (Dawes, 1981; Lüning, 1990). Selain itu, kondisi budidaya pada musim nonproduktif di Teluk Gerupuk, sebagaimana dilaporkan oleh Parenrengi et al. (2011) dapat disebabkan oleh beberapa faktor yang menjadi permasalahan; di antaranya yaitu musim hujan, penyakit ice-ice, gulma, dan pertumbuhan kerdil.

Laju pertumbuhan harian pada akhirnya akan berdampak terhadap tingkat produksi budidaya rumput laut (Gambar 5); tingginya laju pertumbuhan harian keempat varian rumput laut pada musim produktif diikuti oleh

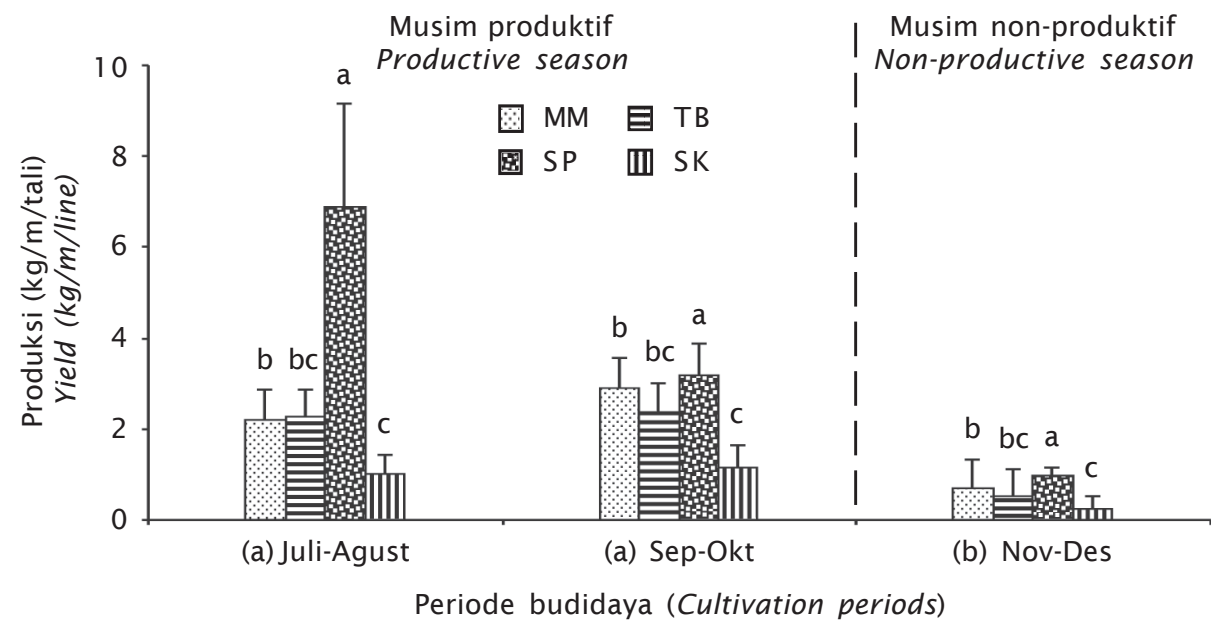

Gambar 5. Rata-rata produksi rumput laut pada tiga siklus budidaya di Teluk Gerupuk (MM: K. alvarezii var. Maumere, TB: K. alvarezii var. Tambalang, SP: Eucheuma denticulatum, SK: K. striatum). Huruf yang berbeda menunjukkan hasil yang berbeda nyata $(\mathrm{P}<0,05)$

Figure 5. Average yield of seaweeds from three cultivation periods in Gerupuk Bay (MM: K. alvarezii var. Maumere, TB: K. alvarezii var. Tambalang, SP: Eucheuma denticulatum, SK: K. striatum). Different letters indicate the significant different of the results $(P<0,05)$ 
tingginya produksi yang dihasilkan (Gambar 3 dan 5). Gambar 5 memperlihatkan rata-rata produksi tertinggi dari dua periode budidaya pada musim produktif dihasilkan oleh $E$. denticulatum $(3,70-7,38 \mathrm{~kg} / \mathrm{m} /$ line $)$ yang berbeda nyata dengan tiga varian lainnya $(\mathrm{P}<0,05)$; kemudian diikuti oleh $K$. alvarezii varian Maumere berkisar 2,70-3,41 kg/m/line; dan $K$. alvarezii varian Tambalang berkisar 2,76$2,89 \mathrm{~kg} / \mathrm{m} /$ line; dan yang terendah adalah $K$. striatum yaitu berkisar 1,50-1,65 kg/m/line (Gambar 5). Tingkatan produksi yang sama juga ditunjukkan oleh keempat varian rumput laut tersebut pada musim non-produktif; hanya saja nilai produksi pada musim non-produktif ini lebih rendah dibandingkan produksi pada musim produktif dengan perbedaan yang signifikan pada $\mathrm{P}<0,05$ (Gambar 5).

Berdasarkan respons laju pertumbuhan harian, pertambahan biomassa, dan produksi yang dihasilkan oleh empat varian rumput laut budidaya pada penelitian ini, E. denticulatum merupakan jenis yang memiliki performa paling baik, yaitu dari segi pertumbuhan dan daya adaptasi terhadap kondisi lingkungan yang menunjukkan perbedaan siginifikan dengan tiga varian lainnya (Gambar 5). Daya adaptasi yang baik terlihat dari laju pertumbuhan, pertambahan biomassa, dan produksi yang selalu tertinggi di antara varian lain baik pada musim produktif maupun musim non-produktif. Keunggulan $E$. denticulatum ini juga dilaporkan oleh Parenrengi et al. (2011), di mana varian ini memperlihatkan pola pertumbuhan yang relatif stabil dibandingkan dengan $K$. alvarezii varian hijau dan coklat yang cenderung menurun pada periode tertentu yang disebabkan oleh penyakit ice-ice. Perbedaan performa rumput laut pada musim tanam yang berbeda merupakan salah satu aspek yang dapat dijadikan pertimbangan dalam pemilihan spesies budidaya yang tepat. Menurut Parenrengi et al. (2011), optimalisasi seleksi spesies rumput laut untuk kegiatan budidaya dapat dilakukan dengan mempertimbangkan beberapa aspek termasuk aspek teknis, musim tanam, dan nilai ekonomis. Spesies yang dipilih merupakan salah satu faktor penentu dari keberhasilan dan keberlanjutan usaha budidaya rumput laut.

Pemilihan jenis rumput laut yang dibudidayakan sangat menentukan jika dilihat dari aspek ekonomis usaha budidaya rumput laut. Pada Tabel 1 terlihat bahwa keempat varian rumput laut yang digunakan pada penelitian

Tabel 1. Volume produksi dan nilai ekonomis dari masing-masing varian rumput laut pada tiga periode budidaya yang berbeda di Teluk Gerupuk, Nusa Tenggara Barat

Table 1. Production volume and economic value of each seaweed varians from different cultivation periods in Gerupuk Bay, West Nusa Tenggara

\begin{tabular}{|c|c|c|c|c|c|c|}
\hline \multirow{3}{*}{$\begin{array}{c}\text { Varian rumput laut } \\
\text { Seaweed varians }\end{array}$} & \multicolumn{3}{|c|}{$\begin{array}{c}\text { Rata-rat a volume produksi } \\
\text { (kg/unit) } \\
\text { Average of production } \\
\text { volume ( } \mathrm{kg} / \text { units) }\end{array}$} & \multicolumn{3}{|c|}{$\begin{array}{c}\text { Rata-rata nilai produksi } \\
\text { (Rp/unit)" } \\
\text { Average of production value } \\
\text { (Rp/units) }\end{array}$} \\
\hline & \multicolumn{6}{|c|}{ Periode budidaya (Cultivation periods) } \\
\hline & Jul-Agt & Sep-Okt & Nov-Des & Jul-Agt & Sep-Okt & Nov-Des \\
\hline MM & 2,756 & 3,643 & 858 & $5,512,250$ & $7,285,900$ & $1,715,250$ \\
\hline TB & 2,829 & 2,988 & 651 & $4,808,450$ & $5,078,963$ & $1,106,960$ \\
\hline SP & 5,723 & 3,185 & 953 & $2,579,400$ & $1,199,325$ & 360,825 \\
\hline SK & 1,255 & 1,442 & 296 & $1,716,900$ & 955,575 & 285,825 \\
\hline
\end{tabular}

Keterangan (Note):

$\mathrm{MM}=K$. alvarezii var. Maumere, $\mathrm{TB}=K$. alvarezii var. Tambalang, $\mathrm{SP}=$ Eucheuma denticulatum, $\mathrm{SK}=K$. striatum (MM: K. alvarezii var. Maumere, $T B=K$. alvarezii var. Tambalang, $S P=$ Eucheuma denticulatum, $S K=K$. striatum)

Perhitungan berdasarkan rata-rata produksi (bobot kering) dan harga pada akhir tahun 2013 . Rendemen bobot kering rumput laut: MM 20\%, TB 17\%, SP 10\%, dan SK 15\% (Komunikasi pribadi: Rusman, M.Si., Pengawas BPBL, Lombok) (Calculation based on production average (dry weight) and product value at the end of 2013 . Seaweeds dry weight rendement: MM 20\%, TB 17\%, SP 10\%, and SK 15\% (Pers. com.: Rusman, M.Si., BPBL, Lombok)) 
ini memiliki tingkat produktivitas budidaya yang berbeda pada musim tanam yang berbeda. Periode tanam Juli-Agustus dan September-Oktober yang termasuk pada musim tanam produktif memberikan hasil produksi yang sangat signifikan lebih baik dibandingkan periode November-Desember yang berada pada musim tanam non-produktif. Berdasarkan harga jual rumput laut pada akhir tahun 2013 di lokasi Lombok Tengah, khususnya di sekitar Teluk Gerupuk, diperlihatkan bahwa jenis Kappaphycus sp. baik varian coklat (MM, TB) maupun varian hijau (SK) memiliki nilai ekonomis yang lebih tinggi dibandingkan $E$. denticulatum (SP). Walaupun E. denticulatum memiliki laju pertumbuhan dan produksi yang tinggi (Gambar 3 dan 5, Tabel 1), namun secara ekonomis nilainya lebih rendah dibandingkan ketiga varian lainnya (Tabel 1). Pada akhirnya, pelaksanaan budidaya rumput laut harus kembali kepada permasalahan yang dihadapi oleh pembudidaya pada setiap lokasi yang menjadi sentra produksi rumput laut. Menurut Parenrengi et al. (2011), identifikasi dan evaluasi permasalahan budidaya harus dilakukan secara cermat terutama dalam hal pemilihan spesies dan penentuan pola tanam yang sesuai dengan karakteristik lokasi budidaya untuk menghindari kegagalan panen dan kerugian bagi pembudidaya.

\section{KESIMPULAN}

Musim tanam merupakan salah satu aspek yang memengaruhi produktivitas budidaya rumput laut. Periode budidaya yang dilakukan pada durasi musim tanam produktif menghasilkan performa budidaya rumput laut yang optimum, sedangkan pada musim non-produktif, walaupun rumput laut masih dapat hidup, namun pertumbuhan relatif sangat lambat dan menghasilkan produktivitas budidaya yang rendah. Berdasarkan performa budidaya empat varian rumput laut yang diuji, $E$. denticulatum merupakan varian yang memiliki performa terbaik pada musim produktif maupun musim non-produktif, dibandingkan tiga varian lainnya, yaitu K. alvarezii varian Maumere, $K$. alvarezii varian Tambalang, dan $K$. striatum. Pemilihan varian rumput laut yang tepat, yaitu berdasarkan performa terbaik dan daya adaptasi tinggi terhadap berbagai kondisi lingkungan, merupakan salah satu kunci keberhasilan budidaya rumput laut yang berkelanjutan, namun tetap dengan mempertimbangkan aspek ekonomis dari sisi usaha budidaya.

\section{UCAPAN TERIMA KASIH}

Terima kasih disampaikan kepada Balai Pengembangan Budidaya Laut, Lombok atas bantuan selama kegiatan di lapangan. Terima kasih juga disampaikan kepada Bapak Buntaran, M.Si., Rusman, M.Si., Seme, dan Teknisi dari Balai Pengembangan Budidaya Laut, Lombok yang telah membantu kelancaran penelitian di lapangan. Kami juga mengucapkan terima kasih kepada Kepala Stasiun Meteorologi Klimatologi dan Geofisika Bandara Internasional Lombok yang telah menyediakan data iklim tahun 2013. Penelitian ini dibiayai oleh DIPA T.A. 2013.

\section{DAFTAR ACUAN}

Ask, E.I. \& Azanza, R.V. 2002. Advances in cultivation technology of commercial eucheumatoid species: a review with suggestions for future research. Aquaculture, 206: 257277.

Banerjee, K., Ghosh, R., Homechaudhuri, S., \& Mitra, A. 2009. Seasonal variation in the biochemical composition of red seaweed (Catenella repens) from Gangetic delta, northeast coast of India. J. Earth Syst. Sci., $118(5)$ : 497-505.

Balai Budidaya Laut [BBL] Lombok. 2012. Petunjuk teknis budidaya rumput laut. Direktorat Jenderal Perikanan Budidaya, Kementerian Kelautan dan Perikanan, $43 \mathrm{hlm}$.

Bulboa, C.R. \& de Paula, E.J. 2005. Introduction of non-native species of Kappaphycus (Rhodophyta, Gigartinales) in subtropical waters: Comparative analysis of growth rates of Kappaphycus alvarezii and Kappaphycus striatum in vitro and in the sea in South-Eastern Brazil. Phycological Research, 53: 183-188.

Dawes, C.J. 1981. Marine botany. John Wiley and Sons, Inc. Canada, 628 pp.

Dawes, C.J., Lluisma, A.O., \& Trono, G.C. 1993. Clonal propagation of Eucheuma denticulatum and Kappaphycus alvarezii for Philippine farms. Hydrobiologia, 260/261: 379-383.

De Silva, S.S. \& Soto, D. 2009. Climate change and aquaculture: potential impact, adaptation and mitigation. In Cochrane, K., De Young, C., Soto, D., Bahri, T. (Eds.), Climate change implication for fisheries and aquaculture: overview of current scientific knowledge. FAO Fisheries and Aquaculture Technical Paper. 530: 151-212. 
Direktorat Jenderal Perikanan Budidaya [DJPB]. 2012. Statistik perikanan budidaya Indonesia. Statprod, No. 13. Kementerian Kelautan dan Perikanan, $116 \mathrm{hlm}$.

Erlania. 2013. Potensi budidaya rumput laut Kappaphycus alvarezii dan Gracilaria gigas dalam penyerapan karbon. Tesis. Sekolah Pascasarjana. Institut Pertanian Bogor. Bogor, $66 \mathrm{hlm}$.

Hurtado, A.Q., Agbayani, R.F., Sanares, R., \& de Castro-Mallare, M.T.R. 2001. The seasonality and economic feasibility of cultivating Kappaphycus alvarezii in Panagatan Cays, Caluya, Antique, Philippines. Aquaculture, 199: 295-310.

Lüning, K. 1990. Seaweed: Their environment, biogeography, and ecophysiology. John Wiley \& Sons, Inc. Canada, 527 pp.

Muñoz, J., Freile-PelegUin, Y., \& Robledi, D. 2004. Mariculture of Kappaphycus alvarezii (Rhodophyta,Solieriaceae) color strains in tropical waters of Yucatán, México. Aquaculture, 239: 161-177.

Parenrengi, A., Rachmansyah, \& Suryati, E. 2011. Budidaya rumput laut penghasil karaginan (Karaginofit). (Edisi revisi). Balai Riset Perikanan Budidaya Air Payau, Badan Penelitian dan Pengembangan Kelautan dan Perikanan, Kementerian Kelautan dan Perikanan. Jakarta, $54 \mathrm{hlm}$.

Radiarta, I N., Erlania, \& Rusman. 2013. Pengaruh iklim terhadap musim tanam rumput laut, Kappaphycus alvarezii, di Teluk Gerupuk, Kabupaten Lombok Tengah, Nusa Tenggara Barat. J. Ris. Akuakultur, 8(3): 453-464.

Raikar, S.V., Lima, M., \& Fujita, Y. 2001. Effect of temperatur, salinity and light intensity on the growth of Gracilaria spp. (Gracilariales, Rhodophyta) from Japan, Malaysia and India. Indian Journal of Marine Sciences, (30): 98-104.

Wong, S.-L. \& Chang, J. 1999. Salinity and light effects on growth, photosynthesis, and respiration of Grateloupia filicina (Rhodophyta). Aquaculture, 182: 387-395.

Scherner, F., Ventura, R., Barufi, J.B., \& Horta, P.A. 2012. Salinity critical threshold values for photosynthesis of two cosmopolitan seaweed species: Providing baselines for potential shifts on seaweed assemblages. Marine Environmental Research, p. 1-12.

Thirumaran, G. \& Anantharaman, P. 2009. Daily growth rate of field farming seaweed Kappaphycus alvarezii (Doty) Doty ex P. Silva in Vellar Estuary. World Journal of Fish and Marine Sciences, 1(3): 144-153. 